\title{
Product differentiation policy of the construction firm
}

Aneta Marichova

\begin{abstract}
Usually, the possibility of product differentiation of the construction company is defined as restricted, limited. Product differentiation as a key element of product policy aims to create a sustainable competitive advantage in the minds of consumers, using tangible and intangible characteristics and product properties compared to the next strongest competitor. The ability of any company to differentiate their own product makes it distinct from competitors and gives the opportunity to control the market and build competitive advantages. The aim of the study is to prove: 1) The need to differentiate the product of the construction company, 2) Guidelines for differentiation of the construction product taking into accounts the specifics of the construction market, product and process.
\end{abstract}

Keywords - construction firm, construction market, differentiation and specialization in specific assets, horizontal and vertical differentiation, product differentiation, positioning

\section{INTRODUCTION}

The possibility of product differentiation in the construction industry is generally defined as limited, limited [1]. Product differentiation as a core element of the company's product policy aims to create a sustainable competitive advantage in the minds of consumers, using tangible and intangible characteristics and product properties compared to the next strongest competitor. The ability of any company to differentiate their own product makes it distinct from competitors and gives the opportunity to control the market and build competitive advantages. Such a company

Manuscript received $1^{\text {th }}$ August 2017

Aneta Marichova - the University of Architecture, Civil Engineering and Geodesy, 1, Hristo Smirnensky Boulevard, 1046-Sofia, Bulgaria (corresponding author e-mail:aneta.marichova@abv.bg, marichova_fte @uacg.bg) 
can raise the price and realize extra profit without losing its customers because it is facing demand with low price elasticity.

Differentiation can be accomplished in the following several ways: horizontal and/or vertical product differentiation, offering additional services, user facilities that increase their social status or his sense of public prestige, flexible pricing policy, increasing the reputation of the company and others. This policy is based on effective segmentation of the market, taking into account the specificities of the market and of the customers, identifying market segments with a clearly defined buyer profile, selecting a target market that meets the company's goals, resources and capabilities, and positioning. Positioning means the company practically differentiates its company offer and to convince its users that it offers the product they want and an extra value higher than that of the competitor. Successful company positioning is done by differentiating the created product into one or a combination of several elements of the marketing mix ("4P") - product, promotion (advertising), price, and distribution. The study of the product policy of the firm has two main objectives: 1) The need for differentiation of the product of the construction company, 2) Guidelines for differentiation of the construction product taking into account the specifics of the market segments in which works construction firm.

\section{NEED FOR DIFFERENTIATION OF THE PRODUCT OF THE CONSTRUCTION FIRM - THEORETICAL ASPECTS}

The product differentiation refers to the degree, in which users of the product it differ of the product of another competing company or have specific preferences to the product of an individual seller [2]. Therefore, it is related to the possibility of product substitutability, which is defined by buyers as an expression of their specific tastes and preferences.

The degree of differentiation determines and the market power of the individual company. The presence of products that are very close substitutes implies weak differentiation and little market power. The presence of small products, which are distinguishable and are therefore not accepted as substitutes by users, implies high differentiation and relatively high market power. A product is differentiated only if the user perceives and distinguishes that product from a differentiating characteristic from the product of a competing firm. The main source of product differentiation is primarily the subjective tastes and preferences of consumers, the information they have, and qualitative characteristics as a source of product differentiation remain in the background. Conditions for differentiation of the product are: relative cost of substitutes, consumer loyalty to the company's proposed product, and switching costs. These are the conditions firms can consciously create their consumers and thus build competitive advantages.

An important factor for product differentiation is the use of unique resources, which guarantees the uniqueness of the product and the advantages of the company. Its product becomes indispensable to consumers, making them less sensitive to the sale price (demand is inelastic).Successful product differentiation is often supported 
by advertising through which each company aims to inform consumers about the products offered or to convince them of its competitive advantage. In this respect, the firm has the opportunity to increase the switching costs and the loyalty of its clients through advertising. Switching costs are costs the user must make when deciding to replace one product used so far with another or to replace one company with another. These costs depend on the time it takes for the user to collect information from other companies about their products, compare it and analyze it to make better choices, and also the time it takes to go to the new chosen company and make the purchase or sign the new contract. If these costs are high, consumers would have less propensity to change the product or company. This allows the company to build strategies to consciously increase switching costs and transforms consumers into loyal customers, which generally increases product differentiation. The high switching costs that consumers have give firms more freedom in setting pricing policies. Therefore, the company's goal is through its product differentiation activity not only to attract consumers but also to make them loyal customers that would not replace the firm product with any other substitute. Therefore, a successful policy of product differentiation is the result of each company's ability to build the following link (Fig.1).

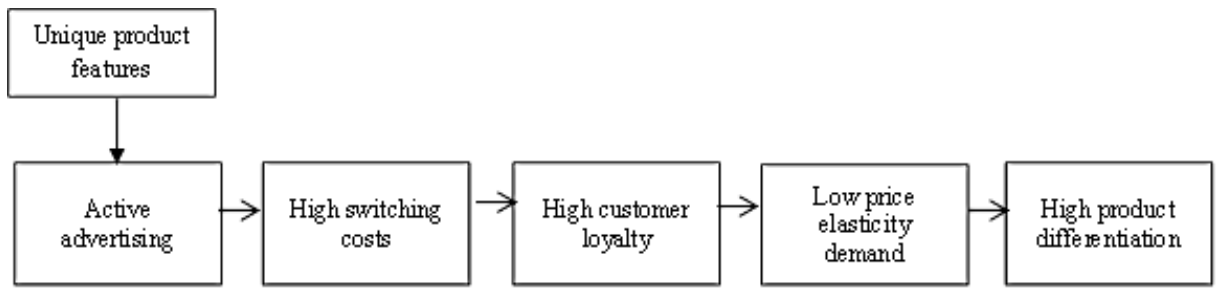

Fig.1. Components and sequence of successful firm policy of product differentiation

In analyzing the differentiation of the construction product, the objective fact that any construction object is created by own project, embodying the idea, the wishes of the investor and the end user, which in the end makes it unique and distinct from all other such products. This suggests that the differentiation of the product in the construction is carried out by the clients/investors themselves in the production process, and not with choice and purchase. The construction company only realizes in projects and in practice the desired ideas, which remains few opportunities for product differentiation by itself.

On the market for building (residential and non-residentia) construction work too many firms with a small market share, limited market power and opportunities for effective product differentiation, therefore their vulnerability to falling demandIs extremely large and for most of them, the problem is simply survival. The goal and direction of each company's development should be solely to create a product, which society wants to consume and meet its specific needs. In this market the main directions for differentiation of the construction product are: differentiation according to basic characteristics and conditions of sale, horizontal and vertical differentiation. 
Product differentiation enables the firm to raise its price and realize additional profit without losing its customers, which means controlling the market and building competitive advantages. Each construction firm can obtain competitive advantages, monopoly power and the realization of monopolistic profit in a short run through quality, reliability, additional services to its users in a short period, i.e. offering a differentiated, unique product. In the long run due to the low barriers to entry and the large number of real and potential competitors on the construction market who can quickly create and offer a similar substitute product, these advantages disappear. The increased number of competing firms reduces the demand for the first firm and its market share. The high degree of substitutability of construction products is a major reason why the benefits of an innovative company turn into traditional characteristics for customers and partners after a short time. This competitive mechanism limits the company's ability to permanently differentiate its own product and gain higher profits over a long period of time. In order to preserve monopoly positions, each company is targeting increasingly fragmented markets, in different parts of the country, thus striving to reduce potential competition. The end result is adapting business behavior to demand fluctuations, but at ever higher costs and decreasing profits.

On the non-residential construction market and part of the market of civil engineering product differentiation is consequence of the specificity of each sector in the economy as a buyer who is looking for a specific, separate construction product. Therefore, the differentiation of these market segments develops mainly in the following directions, which are interconnected and develop and pass from one to another: specialization of the seller's physical assets, localization of the seller and the buyer, close together, specialization of the assets of the Buyer and specialization of human resources. Although due to the peculiarities of the construction as an economic activity creating long-term, specialized tangible assets for all other sectors of the economy, this differentiation is an important factor for the specialization of firms and the commitment to specific service-based buyers based on long-term contracts that stabilize their market positions.

\section{GUIDELINES FOR THE DIFFERENTIATION OF THE CONSTRUCTION PRODUCT TAKING INTO ACCOUNT THE SPECIFICS OF THE MARKET SEGMENT ON WHICH THE CONSTRUCTION FIRM OPERATES}

On the market of building (residential and non-residential) construction, the product differentiation as the main strategy of the construction company can be implemented in the following directions (Fig.2):

1. Horizontal differentiation. The products are similar in quality but have several different key features, that meet different tastes and preferences of consumers. The firm can compete and build its business strategy by constantly changing these particular product features and active commercial impacts on consumers, advertising, promotions and other forms of non-price competition. Horizontal differentiation can be realized and placement and placement and price.

2.Vertical differentiation (by product quality). 
3. Differentiation and specialization in specific assets on the non-residential construction market and part on the market of civil engineering.

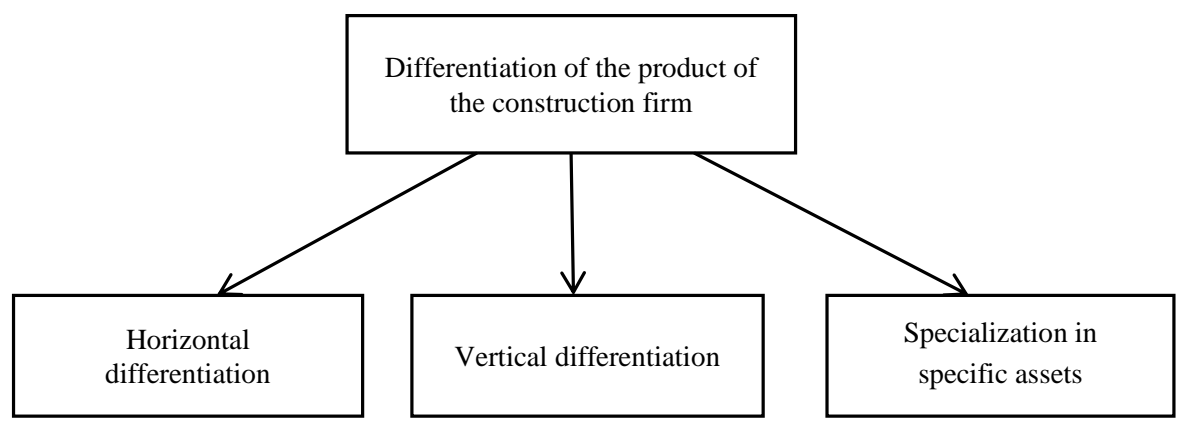

Fig. 2 Guidelines for the differentiation of the construction product

\subsection{Differentiation of the product by main characteristics on the market of building (residential and non-residential) construction}

The product differentiation by main characteristics on the market of building (residential and non-residential) construction is related primarily to the location of the construction object, the uniqueness of the land and the end product created. The right of a construction company received by the owner of the land (private or public) by purchase or payment to build exactly on this terrain is already guarantor for product differentiation in the eyes of consumers. The main factors that influence the choice of users are the location of the construction site (housing and housing cooperative), development of transport infrastructure, security of individual regions, good alternatives for development, work, education of children. They are key in forming a consumer assessment of the degree of differentiation of the construction product, even when it has the same or similar qualitative characteristics with another comparable product.

On the construction market the differentiation of the product is not only the result of objective factors -immobility and connectivity with the land as a specific, scarce resource, but also by the firm's ability to build high customer loyalty. The high cost of construction output the long term of use and the peculiarities of the fact that it is a product, whose characteristics are visible after its consumption, leads users to look for information, compare different alternatives, suggestions, analyze opinions of other users, and carefully make their final choices. All this means that every buyer in this market has a high cost of making a final decision, which determines and the higher costs of switching the company offering the desired product and hence low propensity to shift. The purchase of a new home or its replacement, calculated on average, usually takes place only a few times in life. Customer loyalty to the purchase of durable goods should therefore be seen not only by the consumer or household and an opportunity he directs their friends and relatives to a construction company. The ability of the construction firm to differentiate its product makes its users into customers with high loyalty, which is a guarantee of increased sales, revenues and 
market share. This is a factor that blocks the entrance and shrinks the demand for other firms. In practice, this means growing market power of the operating firm and the opportunity to impose higher prices on this market viewed in a sufficiently long period of time.

Conclusions made for the residential segment, where demand is formed by all households as potential users with multiple, subjective tastes and desires, can be made even more categorically for the segment of non-residential construction. Large investors on this market (especially the construction of the prestigious business and commercial building) have clear preferences and requirements for the desired site, and usually work with several companies based on repeated contracts and transaction specifics. The experience gained in these long-term relationships is a guarantee for the realization of another site of the required quality and within the set time, and this makes one of the construction companies a preferred partner with activity for years to come. The effect of this specialization of the firms is a differentiation of the product and its transformation into a particular, specific, unique product, which provides realization of the corporate goals - maximization of profit.

\subsection{Horizontal differentiation of the product on the market of building (residential and non-residential) construction}

Differentiation of the product, apart from its main characteristics, can also be achieved by the location of the companies, etc. horizontal differentiation. Due to the particularities of construction as an economic activity, the construction firm mainly operates in the region where it is located. Its localization solution is a major factor for the horizontal differentiation of the placement product. The very decision and location of the company is a function of the demand for the final output and the level of competition in the region, and they are in turn a function of the economic activity in the region. If demand is less as a result of weaker economic activity in the region, a relatively small number of companies are localized in the region. To maximize product differentiation, the company must be positioned as close as possible to consumers and as far as possible from competing firms, which enables it to offer and sell at a higher price a product that is unique in its location.

The large number of companies they offer in larger cities increases their competition and reduces the company's ability to differentiate placement products. Every company can build anywhere where he can get terrain and a building permit, whereby the choice of the user is to a large extent randomly, guided only by the preferences available to the home and the price you can pay.

Horizontal product differentiation, apart from placement, can also take place at a location and price that is different according to the different product features quadrature, interior, exterior, additional services offered by the company. These extremely important product features, especially in the case of housing, can cause the user to ignore the good layout at the expense of their better realization. This is a factor that makes the construction firm offer the entire spectrum of different characteristics sought by users, which is a sure guarantee for product differentiation in the eyes of consumers and combined with location reflects on the level of the final price. 
Ultimately, the horizontal product differentiation by placement and price is the result of the company's product policy (determined by the product's characteristics and positioning). In other words, if a specific product is offered and demand is high, the location of the company is irrelevant because its product is differentiated in the eyes of consumers, which also guarantees sales. If the product has characteristics similar to those of the competing product, indistinguishable for consumers, and demand is comparatively weaker main is differentiation placement and the right strategy of the company is maximum distance from other firms. If all companies offer products with comparable, identical features from the point of view of consumers and located close to each other, the product differentiation is minimal, the competition between them is fierce, which means a lower end price.

\subsection{Vertical differentiation of the product on the market of building (residential and non-residential) construction}

Another main direction of product differentiation is vertical differentiation related to quality, raw materials, technologies, know-how [3]. The high quality of a product, which is a guarantor of the high price that the consumer is willing to pay, is associated with the exceptional functionality, durability, reliability of the product, unique selling proposition of the company. The construction company can differentiate your product in a basic, crucial function, and most often it is functionality, convenience of the proposed housing. It can differentiate its product with several different functions, each with a wide range of features or all the features available but with a more limited range of features. In the conditions of a strong decline on the residential construction market, the crisis has no impact on the activity of individual small construction companies with a strong specialization in the creation of a high-quality product unique to the consumers that responds exactly to their tastes and preferences.

With vertical differentiation, consumers perceiveproducts from bottom up, according to the qualitative characteristics andfunctions as the primary connection is "price-quality." The general perception of buyers is that better products have a higher price because of higher production costs, expected benefits and ease of use, etc. Asymmetry of information available to usersSuggests in the case that they can judge the quality only at the price, especially if it is not visible before the purchase and consumption.The desire of consumers to pay a higher price and obtain the higher quality they want can be easily used by the company to convince the consumer that it offers a very profitable deal simply by setting a high price. Companies that are able to offer the product they want can maintain a high price and thus ensure stable market positions even in the conditions of monopolistic competition.

The high quality of the final construction product is a function of the use of high-quality building materials and strict control over the execution of the construction project. Successful vertical differentiation of each product, incl. And construction is mainly the result of effective vertical relationships with suppliers of raw materials and other companies involved in the complex construction process and the creation of an integrated supply chain. It includes companies, organizations, 
activities that are involved in the overall construction process. Every participant in this chain depends on the other involved and co-operation is needed for higher efficiency. This cooperation is achieved through long-term contracts, long-term relationships, links, continuity of joint work and exchange of information. Companies in integrated supply chains exchange information and coordinate within the established chain, which provides maximum benefit to all participants. In addition, accurate estimates are set to execute transactions and to assess the efficiency of the chain. The end results in integrated supply chains are: improving customer service, reducing inventory over the entire chain, offering a better product and higher profits throughout the product lifecycle, and building a competitive edge for participating firms. Integrated supply chains involve competition across supply chains, not between individual companies.

The vertical differentiation of the product and the accompanying competition between companies require that each company finds a way to take a higher place in the consumer's mind by trying to change his beliefs about the brand, especially if he underestimates it and also changes and the attitude, the assessment to competing brands, especially if it is unreasonably high. These are factors that would improve its market position and provide it with competitive advantages.

The products offered on the market combine elements of horizontal and vertical differentiation. Even if users agree that almost all of the features are good, they give a different user rating and evaluate product characteristics differently depending on their preferences. Successful product policy and positioning requires finding the best combination of elements of horizontal and vertical differentiation that users are looking for and satisfying their wishes. This is a factor that creates great opportunities for each company to differentiate its product through different combinations of different product characteristics and to find its market niche (target market).

\subsection{Differentiation and specialization of the construction company in specific assets on the non-residential construction market and part on the market of civil engineering}

The policy of differentiation in specific assets is particularly characteristic on the non-residential construction market and part on the market of civil engineering. The variety of construction products that are offered and must meet the specific demand in the different branches of the economy means that the creation of such production requires the introduction of specific skills, knowledge for design, construction, maintenance and repair of specific objects. Any company that creates such specific end products must have specific internal assets, resources and specific market competencies to enable it to specialize in a specific production and to differentiate its product (according to the specific assets it holds) as required of a particular buyer [4].

Specialization coupled with differentiation and high quality of the product offered (the expression of the vertical differentiation of the product) is a factor and guarantor of stable demand from buyers and of achieving high sales and revenues from the activity and includes: 
1) Physical specialization of the vendor's assets, yho works and specializes only in creating the product that is being sought by her client.

2) The specificity of construction activity and the need to reduce the transport costs impose as the most rational solution and the location specialization of the company, i.e. placing it close to the customer.

3) The specific requirements and specialization of the customer-buyer are imposed by another party to work with one or several companies on the basis of longterm contracts, with clearly stated specifications and requirements, which reduces the transaction costs of both companies.

4) The specialization of the company that it offers and the company it buys End product also require specific knowledge and skills. Human resource specialization in a particular company evolves over time and accumulates experience that is the result of the requirements of a specific activity or the requirements of a particular client. This specialization differentiates and makes the company product distinct, which is a major factor for building competitive advantages.

These four directions of specialization of construction companies by assets, which are the main factor for product differentiation on the non-residential construction market and part on the market of civil engineering are related and interdependent. At the same time, the stable and long-term relationships between the vendor and the buyer of the specialized, differentiated product provide the seller with a monopoly or oligopoly position that ensures stable orders, jobs, stable revenues, competitive positions and benefits and higher profits, even in a period of decline in construction activity. The specificity of the buyer's and/or the seller's assets and their mutual specialization is a major factor for vertical integration.

Extremely high specialization by asset-seller and asset-buyer, and corresponding product differentiation available, mean that both companies would have very high costs and high losses for change of customer and/or supplier. On the one hand, this specialization enables them to meet the specific requirements of the buyers and to maintain their business and, on the other hand, to provide them with a monopoly/oligopoly position in the relevant regional market. For these reasons, firms are typically located close to each other, which means, besides specialization in physical assets and location specialization, which reduces transport costs and ensures external savings. The general conclusion is that the policy of differentiation and specialization in specific assets expressed in the construction of specific construction sites is a function of created distinctive competencies related to production, product and marketing that ensure competitive advantages, stable high profits and profit of the construction firm.

\subsection{Sustainable (green) construction - a basic guideline for differentiation of the construction company's product}

In recent years, new directions for differentiation of the construction product have emerged on the residential market and especially in the non-residential market. However, their realization requires a break with traditional thinking and traditional technologies and demonstrating a sense of concern and an awareness of the environment. The development of sustainable green construction and green infrastructure in all markets includes the following several aspects: 
1) The energy aspect includes not only the cost of the building for itsBut also the cost of manufacturing the products used in it, i.e. the more energy-saving technology is used to produce a product, the more green it is.

2) The economic aspect includes on the one hand the reduction of the totalEnergy costs, resulting in direct economic benefits. On the other hand, the use of energyefficient and recycled materials saves the cost of maintenance and operation of buildings.

3) The environmental aspect is related to the overall environmental assessment of theConstruction production because there are productions which are relatively energy-saving but burden the ecological balance of the Earth.

4) And last but not least in sustainable construction Stands the emotion,the quality of life, the comfort of living in all its aspects - visual, warm, acoustic.Of great importance is also the healthy microclimate of the rooms, where people spend most of their daily lives.

All four aspects of sustainable construction must be considered equally as part of a unified concept.

A key factor for the successful differentiation of the construction company's product through "green" construction and offering "green buildings" to consumers is the development of best practices in the design, implementation, maintenance and reconstruction of buildings. Standard building practices, guided by short-term economic objectives, often show little concern about energy efficiency and economic, social or environmental impacts of the built-up area. Sustainable construction is attempting to end these practices by integrating a wide range of design, construction, operational and maintenance practices to provide a healthier life, a better work environment and to reduce the harmful impact on the environment. Important for the success of sustainable construction is the development and implementation of integrated design principles - the approach to completed building systems that gather key entrepreneurs and professional designers to work together from start to finish. With the traditional design approach, in the initial phase the ability to evaluate a building in its entirety is very small. The uncoordinated work of designers, project managers leads to constant repairs, but sometimes the necessary changes are noticed too late when the construction itself starts and the removal can be much more expensive. Therefore, the possibility of product differentiation in a sustainable construction direction should start from the earliest stages of the project and require the responsible commitment of all actors in the process: designers, administrative authorities, investors and customers, which also requires substantial changes in the organization, coordination and management of the construction firm at all levels.

\subsection{Advertising policy of the construction firm in support of product differentiation}

Strong factor for differentiation of the company's offer and the company's product is advertising. By definition, advertising is intendedTo inform, to persuade, to create attitude and to motivate action. Active information advertising is particularly needed in the construction sector due to the specificity of the product (its characteristics are visible after its consumption) and its main role is to reduce the doubts and tensions of buyers when deciding to make a deal. Persuasion advertising 
differentiated product offerings of the company in the eyes and consciousness of the user, creating additional subjective differences - belonging to a given model of life, social prestige, individualization through the place where he lives and the characteristics of the housing. This sense of exclusivity, resulting from company advertising increases loyalty, the degree of product differentiation and the competitive advantages of the company.

There is a direct relationship and the need for more advertising and more advertising costs with increasing competition and in the conditions of a monopolistic market structure like the competition on the market of building construction. The construction firm operates cyclically as well as the whole economy. Upon a boom in construction its customers are mainly interested in when it will begin and when the object will be completed and the company is too busy with a large number of customers, offers, orders to meet the specific wishes of its customers and offer the product they want. She forgets that by cyclical development there will be changes in the market.When construction is in its decline the company is particularly difficult to return customers or find new ones. In that time she has to fight in a fierce competition with other companies, to win every client by convincing him to offer a product, which exactly matches the specific tastes and preferences. During this period, each company is ready to operate at low profit low income only for survival and preservation of jobs. To prevent this from happening financially suicide, its purpose must be constant active advertising. The construction company tends to save from advertising and reduce its advertising budget when there is a decline in its activity. However, this is the time when it has to actively advertise and increase its advertising costs for activities that increase and maintain customer relations and increase its ability to enter into transactions.

Everything the company advertises must be convincing and with an emphasis on the exclusive proposal, which it does to its customers and with reference to the energy-efficient, green building, which is the most important for consumers today [5].

The product differentiation policy of the construction product includes not only market research and product creation that want and seek consumers but also its training and targeting its preferences in the right direction. This means that the company is not passive, but above all active economic subject who informed about innovations and changing tastes and preferences of consumers. The goal of the construction company should be to educate and shape long-term thinking and assessment of consumer decisions, meaning that the consumer should not think only within a lifetime. Therefore, each responsible company should make consumers think about what property they are buying, how and with what it is built and what it will cost for maintenance after ten years, for example, and whether the owner would then say he still lives in a quality, sustainable or "green" property. In this respect, the role of advertising is decisive, not only informative, but above all convincing and comparative advertising. The user must be well informed to strive to minimize the costs that will be incurred in the future inhabiting their home. 


\section{CONCLUSION}

The paper explores the necessity and the possibilities for differentiation of the construction product. The ability of any company to differentiate their own product makes it distinguishable from competitors and allows control over the market and build competitive advantage. As a result, it can increase the price and make extra profit without losing its users,Because it faces a sufficiently steep individual demand curve with low price elasticity. Product differentiation, however, should take into account the specificity of the market segment where the company operates. From this point of view, the conclusion of the author is that the main factor for the differentiation of the product on the market of building (residential and nonresidential) construction is the location of the building site, the uniqueness of the land and the created end product, but also additional services, user facilities, which increase his social status or his sense of public prestige, with what functions in principle is laden housing, active advertising, increasing the reputation of the company and the ability to build high loyalty to consumers. Product differentiation, apart from its main features, can also be achieved through horizontal differentiation and vertical differentiation (product quality), which is the most complex problem in the construction market and requires constant control. On the market of building (residential and non-residential) construction, which is operated by too many companies with a small market share, limited market power, the guidelines for differentiation of the construction product create great opportunities for each company to differentiate its product through various combinations of elements from the horizontal And the vertical differentiation that users are searching for from the relevant target market and satisfies their wishes.

The policy of differentiation on specific assets (typical for the non-residential construction market and part of the civil construction market) is geared to meeting the specific demand in the different branches of the economy.

Each firm that creates a specific end product must have specific internal assets, resources, and specific market competencies to enable it to specialize in a specific production and to differentiate its product (according to the specific assets it owns) that meets the requirements of a specific buyer. The specialization, differentiation and high quality of the product offered (the expression of the vertical differentiation of the product) is a factor and guarantor of stable demand from buyers and of achieving high sales and income from the activity.

In recent years, a new direction for differentiation - sustainable construction has emerged on the residential market and especially on the non-residential construction market. The differentiation of the construction product requires significant changes in the construction company's activity - breaking with traditional thinking and traditional technologies, developing long-term economic objectives and new practices that imply the application of integrated design principles - active involvement and participation of all subjects in the construction process from the beginning to the end. 


\section{REFERENCES}

[1] Bain J., (1968), Industrial Organization. 2nd edition. John Wiley \& Sons. New York.,pp.223

[2] Myers D. (2008), Construction Economics: A new approach. Second Edition. Taylor \& Francis. London \&New York, pp. 145-151

[3] Piana V., (2003), Product Differentiation, Economics Web Institute, jan.1, Stefan L., (1997), Vertical product differentiation and entry deterrence, Journal of Economics, Springer, vol. 65(1), pp. 79-102

[4] Stoun M., (2011), How and when to advertising a construction business. Deluxe for business.

[5] Williamson O., (1985), The Economic Institutions of Capitalism. New York: Free Press. 